\title{
Anti- hypertensive activity of Ayurvedic medicinal plants
}

\begin{abstract}
Hypertension is a chronic non communicable disease and often asymptomatic medical condition in which the pressure exerted by the blood on the wall of the artery is elevated. It is chiefly of unknown aetiology, but genetic factors play significant role for its development. Uncontrolled hypertension is a risk factor for various pathological conditions such as heart attack, heart failure, stroke, retinal haemorrhage and kidney disease. In Ayurveda a number of medicinal plants and Ayurveda compound formulations have been prescribed by Ayurveda doctors for the treatment of hypertension. The therapeutic efficacy of those plants has also being verified by using modern pharmacological experimental models. This paper reviews various clinical and experimental studies conducted in the last few decades on plants showing anti-hypertensive property.
\end{abstract}

Keywords: Ayurveda, hypertension, medicinal plants, heart failure, stroke, retinal haemorrhage, kidney disease
Volume I 3 Issue I - 2020

\author{
Hari Khanal, Ram Kishor Joshi, Abhishek \\ Upadhyay \\ Department of Kayachikitsa, National Institute of Ayurveda, \\ India
}

Correspondence: Hari Khanal, PG Scholar, Department of Kayachikitsa, National Institute of Ayurveda, Jaipur, Rajasthan, India, Email khanalhari06@gmail.com

Received: November 20, 2019 | Published: January 10, 2020

\section{Introduction}

The pressure exerted on the wall of arteries by the strength of the contraction of the heart is called Blood Pressure. ${ }^{1}$ Hypertension is a lifestyle disease that is characterized by abnormally high arterial blood pressure that is usually indicated by an adult systolic blood pressure of $140 \mathrm{~mm} \mathrm{Hg}$ or greater or a diastolic blood pressure of $90 \mathrm{~mm} \mathrm{Hg}$ or greater. ${ }^{2}$ It is chiefly of unknown aetiology but may be due to a pre-existing condition such as a renal or endocrine disorder, that typically results in a thickening of arterial walls and hypertrophy of the left heart ventricle. ${ }^{3}$ Uncontrolled hypertension is a risk factor for various pathological conditions such as heart attack, heart failure, stroke, kidney disease and retinal haemorrhage. ${ }^{4}$ The disease has been appropriately nicknamed 'silent-killer' because in most patients hypertension does not have any symptom and usually goes unnoticed. ${ }^{5}$ Hypertension is a global health problem. Worldwide, approximately $26.4 \%$ of the adult population in 2000 had hypertension ( $26.6 \%$ of men and $26.1 \%$ of women), and $29.2 \%$ were projected to have this condition by 2025 (29.0\% of men and $29.5 \%$ of women). The estimated total number of adults with hypertension in 2000 was 972million; 333million in economically developed countries and 639 million in economically developing countries. The number of adults with hypertension in 2025 was predicted to increase by about $60 \%$ to a total of 1.56 billion. ${ }^{6}$

In ancient Ayurveda texts, we cannot find a word corresponding to hypertension. Academicians have suggested different names to demonstrate the phenomenon. These names include Raktagata vata, Rakta Vikshepa, Shiragata Vata, Avrita Vata, Rakta Chapa, Rakta Sampida, Vyana Bala, Dhamani pratichaya, Dhamani Prapurnata, Rasa Bhara, Rakta Vriddh, Rudhira Mada and Raktavata ${ }^{7}$. In the management of hypertension, Ayurveda has certain limitations especially in the emergency management for the hypertensive crisis and other vascular episodes. However, a number of studies have suggested that Ayurveda can effectively treat chronic hypertensive conditions.

\section{Aims and objectives}

Despite the massive investment in drugs and therapeutics for the management of hypertension, its prevalence is increasing at an alarming rate. Human race today is looking towards Ayurveda in search of effective, sustainable and safe treatment. Hence, to get the appropriate management of hypertension without any side effects is a need of hour. In this context, the objective of this study is to review past studies with the emphasis on anti-hypertensive actions of medicinal plants and recent approaches to validate their antihypertensive efficacies.

\section{Material and methods}

This study is based on the systematic review of literature published in national and international journals. We reviewed various researches on medicinal plants that have been utilized in the management of hypertension and their ultimate results. For this review, the research article published on anti-hypertensive ayurvedic medicinal plants during 1954 to August 2019 were explored through online internet searches, including scientific database such as Google Scholar, PubMed and others. The main keywords used for searching articles included: hypertension, blood pressure, medicinal plants, Ayurvedic herbs and traditional herbal medicine.

\section{A. Inclusion criteria}

Inclusion criteria adapted for this study are given below

\section{a. Clinical studies}

Study duration: at least one month

Patients/volunteers: more than 15

Outcomes: clearly indicated in terms of efficacy and safety.

Publication language: English 


\section{b. In Vivo animal studies}

Outcomes: Containing mode of action and efficacy

Protocol: Well- defined in terms of doses and formulation type

Publication language: English

\section{B. Exclusion criteria}

The exclusion criteria considered for this review were:
a. Patient/volunteers less than 15
b. Studies without scientific data
c. Language: Other than English

\section{Results and discussion}

This section presents the results of the study and discusses a number of medicinal plants that have been reported to be effective in the management of hypertension.

\section{A. Ajmoda}

Latin name: Carum roxburghianum Graib.

Family: Umbelliferae

Chemical composition: Meethers of thymol, Carvacrol, $3 \mathrm{nB}$ and Thymoquinol.

\section{Parts use: Seeds}

Mechanism of action: In one animal study, $3 \mathrm{nB}$ appears to lower blood pressure by acting as both a diuretic and vasodilator through impacting the production of prostaglandins, as well as acting in a similar manner to calcium-channel blockers. ${ }^{8}$

In another study $75 \mathrm{mg}$ per capsule of a celery seed extract was given in a dose of 1 capsule bid to mild to moderate hypertensive patients. After 3 weeks of intake there was significant decrease in systolic blood pressure of $4.6 \mathrm{mmHg}(\mathrm{P}<0.005)$ and diastolic blood pressure of $4.5 \mathrm{mmHg}(\mathrm{P}<0.005)$ compared to baseline. Similarly after 6 weeks of intake, the decrease in SBP and DBP compared to baseline was 8.9 and $8.5 \mathrm{mmHg}$, respectively $(\mathrm{P}<0.005)$. This is statistically highly significant effect of celery seed extract in the management of hypertension. ${ }^{9}$

\section{B. Arjun}

Latin name: Terminalia arjuna (Roxb.) W \& A)

Family: Combretaceae

Chemical composition: Tannins, Triterpenoid Saponins, Flavonoids, Gallic acid, Ellagic acid, OPCs, Phytosterols, Calcium, Magnesium, Zinc and Copper

\section{Parts use: Bark}

Mechanism of action: Numerous studies have elucidated Terminalia arjuna effects on various cardiac disorders including myocardial infraction, angina pectoris, hypertension, congestive heart failure and coronary artery disease. The effect of bark powder of T. arjuna, on blood pressure, anginal frequency, body mass index, blood sugar, cholesterol and HDL cholesterol was studied in 15 stable and 5 unstable angina patients for 3 months. It lowered systolic blood pressure and BMI to a significant level $(\mathrm{p}<0.05)$ and increased HDLcholesterol only slightly along with marginal improvement in left ventricular ejection fraction instable angina patients ${ }^{10}$.

\section{Ashwagandha}

Latin Name: Withania somnifera Linn.

Family: Solanaceae

Chemical composition: Cuseohygrine, Anahygrine, Anaferine, Isopellertierine, Withanolides, Withaferins, Saponins

Parts use: Root

Mechanism of action: one study was conducted to see the difference of antihypertensive effect of Ashwogandha root powder with milk and water. The blood pressure of group I and group II were compared before and after supplementation. Mean systolic blood pressure of group I and group II before supplementation was $164 \mathrm{mmHg}$ and $157 \mathrm{mmHg}$ respectively whereas after supplementation mean systolic blood pressure decreases to $158 \mathrm{mmHg}$ for group I and $154 \mathrm{mmHg}$ for group II. Mean diastolic blood pressure of group I and group II before supplementation was $100.50 \mathrm{mmHg}$ and $101.2 \mathrm{mmHg}$ respectively whereas after supplementation mean diastolic blood pressure decreased to $85 \mathrm{mmHg}$ for group I and $92 \mathrm{mmHg}$ for group II. Decrease in diastolic pressure was significant in both the group but differences were greater for patient in group I than for patient in group II. This study shows that Ashwagandha with milk is more effective in decreasing blood pressure in hypertensive patients than Ashwagandha with water. ${ }^{11}$

In another study the effect of Ashwagandha was studied on the cardiovascular and respiratory systems in dogs and frogs. The study found that the alkaloids had a prolonged hypotensive, bradycardiac, and respiratory-stimulant action in dogs. The hypotensive effect was mainly due to autonomic ganglion blocking action and depressant action on the higher cerebral centers. ${ }^{12}$

\section{Gokshura}

Latin name: Tribulus terrestris Linn.

Family: Zygophyllaceae

Chemical composition: Protodioscin, Beta- carbolinea alkaloids Harman and norharman.

Parts use: whole plant and fruits

Mechanism of action: A study was conducted with 75 patients of either sex, different age groups having non-complicated, mild to moderate essential hypertension with the symptoms of headache, giddiness, insomnia etc. The test drug i.e whole plant and fruits of Gokshura in the form of ghanasatwa (solid water extract) was given orally to the Group A\&B respectively, at the dose of $3 \mathrm{gm} /$ day in three divided doses for four weeks and assessment was made at the end of every week. The results of both subjective and objective parameters of the study reveals that both the whole plant and fruits of Gokshura had a significant action in reduction of clinical symptoms, systolic and diastolic blood pressure without any side effects on the patients of mild to moderate essential hypertension. Therefore, this plant diuretic can be safely recommended for a longer period to the patients of mild to moderate hypertension. ${ }^{13}$

\section{E. Jatamamsi}

Latin name: Nordostachys jatamansi DC.

Family: Valerianaceaea.

Chemical composition: Jatamansika, Jatamansine, 


\section{Parts use: Rhizome}

Mechanism of action: In an open clinical trial 20 patients of grade-I and grade-II uncomplicated essential hypertension of either sex aged between 25-70years, were given Jatamamsi Churna in a dose of 10 grams per day in two equal divided doses. After 60days of therapy mean systolic blood pressure which was $148.9 \mathrm{~mm}$ of $\mathrm{Hg}$ before treatment was reduced to $132.6 \mathrm{~mm}$ of $\mathrm{Hg}$ and mean diastolic blood pressure was reduced to $97.1 \mathrm{~mm}$ of $\mathrm{Hg}$ to $86 \mathrm{~mm}$ of $\mathrm{Hg}$. Reduction in both systolic and diastolic blood pressure was statistically highly significant $(\mathrm{P}<0.001)$. Pharmacological studies have also revealed its central depressant action and vascular smooth muscle relaxation properties. So probably Anti-hypertensive action of Jatamamsi is mediated partly through reduction in cardiac output and partly through reduction in peripheral resistance. ${ }^{14}$

\section{F. Jeera (Black cumin )}

Latin Name: Nigella sativa

\section{Family: Ranunculaceae}

Chemical composition: Thymoquinone, Dithymoquinone, Thymohydroquinone, Thymol 32, Carvacrol, t- anethole and 4terpineol. Hypotensive action of Nigella is mainly due to its volatile oils.

\section{Parts use: Seeds}

Mechanism of action: In an animal study, an oral dose of Nigella sativa extract $(0.6 \mathrm{ml} / \mathrm{kg} /$ day $)$ and furosemide $(5 \mathrm{mg} / \mathrm{kg} /$ day $)$ increased significantly the diuresis by 16 and $30 \%$ respectively after 15 days of treatment; urinary excretion of $\mathrm{Cl}-, \mathrm{Na}+, \mathrm{K}+$ and urea is also increased. In the same study the mean arterial pressure decreased respectively by 22 and $18 \%$ in the Nigella sativa treated rat and nifédipine treated rat $(0.5 \mathrm{mg} / \mathrm{kg} / \mathrm{day})$. In conclusion, the diuretic activity observed in the SHR rat treated with Nigella sativa seeds may be partially responsible for its diuretic action and antihypertensive action; it seems that other pathways may also be involved in their cardiovascular effects. ${ }^{15}$

\section{G. Kesar (Saffron )}

Latin name: Crocas sativus

Family: Iridaceae

Chemical composition: Crocin, Picrocrocin and Safranal

Parts use: Stigmas, petals

Mechanism of action: In one animal study, researcher investigated the effects of Crocus sativus petals extract on blood pressure in anaesthetised rats and also on responses of the isolated rat vas deferens and guinea-pig ileum induced by electrical field stimulation (EFS). Aqueous and ethanol extracts of $C$. sativus petals reduced the blood pressure in a dose-dependent manner. Administration of $50 \mathrm{mg} / 100 \mathrm{~g}$ of aqueous extract changed the blood pressure from $133.5+/-3.9$ to $117+/-2.1(\mathrm{mmHg})$. EFS of the isolated rat vas deferens and guinea-pig ileum evoked contractions were decreased by aqueous and ethanol extracts of C. sativus petals. The aqueous extract $(560 \mathrm{mg} /$ $\mathrm{ml}$ ) significantly reduced the contractile responses of vas deferens to epinephrine $(1 \mathrm{microM})$ without any change in contraction induced by $\mathrm{KCl}(300 \mathrm{mM})$. This results may suggest that the relaxatory action of $C$. sativus petals extract on contraction induced by EFS in the rat isolated vas deferens is a postsynaptic effect. ${ }^{16}$

\section{H. Lasun (Garlic)}

Latin name: Allium sativum L.

Family: Amaryllidaceae

Chemical composition: S- allyl-cysteine sulfoxides, Ajoene, Allicin, Alliin, Allixin, Methyl allyldisulfide

\section{Parts use: Rhizome}

Mechanism of action: In one animal study, it was found that intravenous infusion of garlic extract reduces blood pressure and heart rates in both hypertensive and normotensive rats. This study also provides evidence that garlic reduces blood pressure in a dose dependent manner by a mechanism not involving acetylcholine. As a part of safety evaluation, this study was performed to verify the effects of garlic in hemodynamic parameters, particularly in relation to its effects on blood pressure and heart rate. The results showed that garlic at higher doses $(15$ and $20 \mathrm{mg} / \mathrm{kg})$ induced marked hypotension and bradycardia when injected intravenously whereas at a lower doses (5 and $10 \mathrm{mg} / \mathrm{kg}$ ) it produced only a slight and insignificant fall in mean arterial pressure. Various mechanisms for antihypertensive effect of garlic have been reported to include vasorelaxation through $\mathrm{H} 2 \mathrm{~S}$ production, inhibition of angiotensin-converting enzyme in vitro endothelium and beta-adrenoceptor blocking action. ${ }^{17}$

\section{Makandi (forskolin)}

Latin Name: Coleus forskohlii / Plectranthus barbatus

Family: Lamiaceae

Chemical composition: coleonol

\section{Parts Use: Root}

Mechanism of action: Forskolin has been used in Ayurvedic medicine for many years. In 1974, the Indian Central Drug Research Institute discovered that forskolin, a component of this plant, has hypotensive and antispasmodic action. Forskolin's blood pressure lowering effects appear to be due to relaxation of arterial vascular smooth muscle. In a study with isolated heart tissue, Forskolin activated membranebound adenylatecyclase and cytoplasmic cAMP-dependent protein kinase. The researchers postulated the positive inotropic effect was via an enhanced calcium uptake by the heart muscle cell. Another constituent from Coleus, ditermene coleonol, has been found to lower blood pressure in both rat and cat models. ${ }^{18}$

\section{J. Mandukparni}

Latin name: Centella asiatica (L) Urban

Family: Apiaceae

Chemical composition: Pentacyclic triterpenoids, Asiaticoside, Quercetin, Brahmoside, Asiatic acid, Brahmic acid, Centellose, Centelloside and Madecassoside.

Parts use: Whole Plant

Mechanism of action: In one animal study, researcher assessed effects of Centella asiatica extract on blood pressure and heart rate (HR) of N-nitro-L-arginine methyl ester (L-NAME) induced hypertensive rats. Male Wistar rats were anesthetized with sodium pentobarbital $(50 \mathrm{mg} /$ $\mathrm{kg}$, i.p.) and their left carotid arteries were cannulated for invasive blood pressure measurement. Mean arterial blood pressure (MABP), 
systolic blood pressure (SBP), diastolic blood pressure (DBP), and HR were recorded continuously throughout the experiment using PowerLab system. A single intragastric administration of Centella asiatica extract $(4,8$ and $32 \mathrm{~g} / 20 \mathrm{ml} / \mathrm{kg})$ did not cause changes in MABP, SBP and DBP. At 90 min after administration, Centella asiatica extract $(16 \mathrm{~g} / 20 \mathrm{ml} / \mathrm{kg})$ significantly decreased the elevated MABP and DBP. ${ }^{19}$

In another animal study, Long-term quercetin, a flavonoid found in Centella asiatica administration induced a progressive reduction in SBP in SHR and this effect reached statistical significance after the first week of treatment while no changes were observed in WKY rats. At the end of the 5 weeks of treatment, direct measurements of blood pressure in conscious rats showed that quercetin induced a significant reduction in systolic (-18\%), diastolic (-23\%) and mean $(-21 \%)$ arterial blood pressure in SHR. Heart rate was also significantly reduced by quercetin in SHR (-12\%). This antihypertensive effect was may be due to direct vasodilator action of quercetin and related bioflavonoids. ${ }^{20}$

\section{K. Punarnava}

Latin name: Boerhavia diffusa Linn.

\section{Family: Nyctaginaceae}

Chemical composition: Lirridodendrin \& Hypoxanthine.

Parts use: Whole plant, root

Mechanism of action: In one clinical trial, $250 \mathrm{mg}$ of Punarnava extract was given orally in a dose of 2 capsules twice in a day with water for six weeks. It has shown statistically significant reduction of mean Systolic and diastolic BP. Before treatment mean SBP was $151.48 \pm 5.75$ and it reduced to $137.33 \pm 5.23$, similarly before treatment mean diastolic BP was $95.41 \pm 2.06$ which reduced to $87.11 \pm 4.75$. It is due to Liridodendrin, Hypoxanthine and boeravinones which are active antihypertensive agents of Punarnava which acts as $\mathrm{Ca}+2$ channel antagonist. It also acts as diuretic by increasing renal blood flow by relaxing the smooth muscles of the arterial wall. ${ }^{21}$

\section{Rudrakshya}

Latin name: Elaeocarpus ganitrus

Family: Elaeocarpaceae

Chemical composition: Elaeocarpidine, Isoelaeocarpine, Rudarakine, Flavonoids, Gallic acid, Quercetin

Parts use: Fruit and Bark

Mechanism of action: An aqueous extract of E.ganitrus seeds given intravenously in hypertensive rats at the dose levels of 25, 50 and $100 \mathrm{mg} / \mathrm{kg}$. It shows significant $(\mathrm{p}<0.05)$ decreased in the elevated blood pressure in dose dependent manner. The antihypertensive activity of aqueous extract of E. ganitrus may be due to the action on rennin-angiotensin system. ${ }^{22}$

\section{Sahachar}

Latin name: Barleria prionitis

Family: Acanthaceae

Chemical composition: Alkaloids, Flavonoids, Methanolic, Saponins, Tannin and Phenolic compounds

Parts use: Whole plant
Mechanism of action: In vivo anti-hypertensive study using DOCA salt induced hypertensive rats, methanolic extracts of Barleria prionitis possessed profound antihypertensive activity in dose of $200 \mathrm{mg} /$ body weight and $400 \mathrm{mg} /$ body weight. ${ }^{23}$

\section{N. Sarpagandha}

Latin name: Rauwolfia serpentina Benth ex. Kurz

Family: Apocynaceae

Chemical composition: Ajmalidine, Ajmaline, Ajmalinine, Ajmalicine, Rauwolfinine, Recanescine, Rescinnamine, Reserpiline, Reserpine, Reserpinine, Sarpagine, Serpentine, Serpentinine, Thebaine, Vohimbinine.

\section{Parts ise: Root}

Mechanism of action: In a clinical trial of Rauwolfia serpentina in essential hypertension, researcher treated 50 patients with initial blood pressures greater than $160 / 95 \mathrm{~mm} \mathrm{Hg}$. Tablets of the dried root of R. serpentine was prescribed in optimum doses. Within a week of treatment, 77 percent cases showed a drop of systolic blood pressure ranging from 2 to $38 \mathrm{~mm}$. with an average drop of $13 \mathrm{~mm}$. A drop of $10 \mathrm{~mm}$. or over was noted in 40 per cent of cases. In the case of the diastolic blood pressure, 73 percent of cases displayed a drop ranging from 2 to $18 \mathrm{~mm}$. with an average drop of $6 \mathrm{~mm}$. a diastolic response of $5 \mathrm{~mm}$. or over was noted in 35 percent. In 73 percent of cases, there was a drop of both systolic and diastolic blood pressure after one week of therapy. After four weeks of treatment, 85 per cent of cases displayed a drop of systolic blood pressure varying from 2 to $54 \mathrm{~mm}$. with an average of $21 \mathrm{~mm}$. A systolic drop of $10 \mathrm{~mm}$. or over was noted in as many as 74 percent of cases. In 81 per cent of cases, the diastolic pressure showed a drop of 4 to $34 \mathrm{~mm}$. with an average of $11 \mathrm{~mm}$. A diastolic fall of $5 \mathrm{~mm}$. or over was noted in 72 per cent. In 62 per cent of cases there was a significant drop of both systolic and diastolic pressure levels. The hypotensive action of the drug was perceptible at 2 weeks after stopping the drug in $91 \%$ of patients and at 4 weeks after discontinuing the drug in $75 \%$ of patients. No serious adverse side effects were noted. ${ }^{24}$

Another study was conducted to evaluate various effects of oral reserpine on a group of hypertensive patient in an outpatient clinic. Reserpine from CIBA Pharmaceuticals was given to fifteen patient who had initial blood pressures between $160 / 98$ and 240/150mm Hg in a dosage of $20 \mathrm{mg}$ twice a day. The result shows systolic blood pressure reduced an average of $30.7 \mathrm{~mm} \mathrm{Hg}$ and diastolic blood pressure reduced an average of $19 \mathrm{~mm} \mathrm{Hg}$. Some patients reported transient nausea, fainting, and dyspnoea. The researchers concluded that the drug was a useful and potent agent in some patients with severe as well as mild hypertension ${ }^{25}$.

\section{O. Vacha}

Latin Name: Acorus calamus L.

Family: Acoraceae

Chemical composition: Beta- Asarone, Beta- Gurjunene, Asarone. Sequesterpenes, Beta- Daucosterol, Xylose, D- Galacturonic Acid.

\section{Parts use: Rhizome}

Mechanism of action: In normotensive rats under anaesthesia, intravenous administration of crude extract of A. calamus caused 
a fall in mean arterial pressure. The percent fall in MAP at the respective doses of 10,30 , and $50 \mathrm{mg} / \mathrm{kg}$ was $18.86 \pm 60.48,27.50 \pm 6$ 0.97 , and $42.25 \pm 61.0$ and was statistically different $(\mathrm{P}<0.05)$ at doses of 30 and $50 \mathrm{mg} / \mathrm{kg}$ in comparison to $10 \mathrm{mg} / \mathrm{kg}$. This show that crude extract possesses a combination of effects, relaxant effects mediated possibly through $\mathrm{Ca}+2$ antagonism in addition to a nitric oxide pathway. Calcium channel antagonist prevents the intracellular inflow of calcium resulting in smooth muscle relaxation and decrease in heart rate, which eventually contributes for lowering the blood pressure. Similarly, nitric oxide is responsible for vasodilation that is essential for controlling blood pressure. ${ }^{26}$

\section{P. Visnukrantha (Blue Sankhapuspi)}

Latin name: Evolvulus alsinoides Linn.

Family: Convolvulaceae

Chemical composition: Scopoletin, Umbelliferone, Scopolin etc.

Parts use: Root, Whole plant

Mechanism of action: In vivo anti-hypertensive study using DOCA salt induced hypertensive rats, methanolic extract of Evolvulus alsinoides shows significant antihypertensive effect. SBP, DBP, MABP and PP were significantly decreased in MEEA treated rats as compared to disease control group enalapril $(p<0.001 / p<0.01 /$ $\mathrm{p}<0.05$ ). The antihypertensive effect may be due to ACE inhibitor mechanism of Evolvulus alsinoides herb extract because the extract lowers the blood pressure as similar to enalapril which is an ACE enzyme inhibitor ${ }^{27}$.

\section{Q. Yarrow}

Latin name: Achillea millefolium L.

Family: Asteraceae

Chemical composition: Flavonoids and Sesquiterpene lactone

Parts use: Leaves with flowering shoots, Flowers and Steam

Mechanism of action: A double-blind, placebo-controlled trial was conducted to see the antihyperlipidemic and antihypertensive effects of Achillea. This shows mild decrease in triglycerides after two months, and significant decreases in triglycerides and total- and LDL- cholesterol after four months. Levels of HDL-cholesterol were significantly increased after six months treatment. Similarly, it shows significant reduced in systolic and diastolic blood pressure after two and six months, respectively $(\mathrm{p}<0.05) .^{28}$

\section{Conclusion}

Hypertension is one of the leading health problems worldwide. This has been identified as one of the major cause of death in developed and developing countries. Moreover, the number of patients suffering from hypertension is increasing, and conventional medicine has not been effective in successfully treating the disease. Over the recent decades, Ayueveda medicinal plants have been proven to be effective in lowering blood pressure and improving heart functions. Some drugs are proved experimentally but numerous are yet to be revealed. This review article documented a number of medicinal plants and their mode of actions that have been reported to be effective in the management of hypertension in the field of Ayurveda. The study finds that the most researched and frequently utilized medicinal plants for the treatment of hypertension are Sarpagandha, Jatamamsi, Gokshura,
Arjuna, Lasun, Vacha and Ashwagandha. Furthermore, we find that there are scientific evidences of the use of some medicinal plants for the treatment of the disease. From the number of researches carried out at various institutions all over the world, it is clear that there is a lot of potential in herbal medicine to control hypertension. We believe that this review study will provide a basis for further scientific study to investigate the use of different plants in the treatment of different health issues. Thus, this kind of study will ultimately boost the use of traditional remedies due to an array of scientific evidence in its favour.

\section{Acknowledgments}

None.

\section{Conflicts of interest}

There are no any conflicts of interest.

\section{Funding}

None.

\section{References}

1. Davis FA. Tabers Cyclopedic Medical Dictionary. 20 ${ }^{\text {th }}$ edn. 2005, p. 268.

2. Chobanian AV, Bakris GL, Black HR, et al. The seventh Report of the Joint National Committee on Prevention, Detection, Evaluation and Treatment of High Blood Pressure: the JNC 7 report. JAMA. 2003;289(19):2560-2572.

3. Burt VL, Whelton P, Roccella EJ, et al. prevalence of hypertension in the US adult population. Results from the third National health and Nutrition Examination Survey, 1988-1991. Hypertension. 1995;25(3):305-313.

4. De Geest S, Sabaté E. Adherence to Long-term therapies: evidence for action. Eur J Cardiovasc Nurs. 2003;2(4):323.

5. Vivian EM. Improving blood pressure control in a pharmacist managed hypertension clinic. Pharmacotherapy. 2002;22(12):533-540.

6. Kearney PM, Whelton M, Reynolds K, global burden of hypertension: analysis of worldwide data. Lancet. 2005;365(9455):217-223.

7. Rathod MR, Kumar SA. Understanding of Hypertension in Ayurveda. $J$ Altem and Integ Med. 1201;1(1):494.

8. Tsi D, Tan BKH. Cardiovascular pharmacology of 3-n-butylphthalide in spontaneously hypertensive rats. Phytotherapy Reasearch. 1997;11:576-582.

9. Madhavi D, Kagan D, Rao V, et al. A Pilot Study to Evaluate the Antihypertensive Effect of a Celery Extract in Mild to Moderate Hypertensive Patients. Natural Medicine Journal. 2013;4(4).

10. Dwivedi S, Agarwal MP. Antianginal and cardioprotective effects of Terminalia arjuna, an indigenous drug, in coronary artery disease. $J$ Assoc Physicians India. 1994;42(4):287-289.

11. Kushwaha S, Betsy A, Chawla P. Effect of Ashwagandha (Withania somnifera) Root Powder Supplementation in Treatment of Hypertension. Ethno Med. 2017;6(2):111-115.

12. Ojha SK, Arya DS. Withania somnifera Dunal (Ashwagandha), A promising remedy for cardiovascular diseases. World J Med Sci. 2009;4(2):156-158.

13. Murthy AR, Dubey SD, Tripathi K. Anti-hypertensive effect of Gokshura (Tribulus terrestris Linn.) A clinical study. Anc Sci Life. 2000;19(3-4):139-145. 
14. Venkata Krishna Naik. Clinical Evaluation of Jatamamsi Churna in the Management of Essential Hypertension. International Journal of Ayurveda and Pharma Research. 2016;4(6):92-94.

15. Zaoui A, Cherrah Y, Lacaille-Dubois MA. Diuretic and hypotensive effects of Nigella sativa in the spontaneously hypertensive rat. Therapie. 2000;55(3):379-382.

16. Fatehi M, Rashidabady T, Fatehi-Hassanabad Z. Effects of Crocus sativus petals' extract on rat blood pressure and on response induced by electrical field stimulation in the rat isolated vas deferens and guineapig ileum. J Ethnopharmacology. 2003;84(3-3):199-203.

17. Nwokocha CR, Ozolua RI, Owu DU, et al. Antihypertensive properties of Allium sativum (garlic) on normotensive and two kidney one clip hypertensive rats. Niger J Physiol Sci. 2011;26(2):213-218.

18. Dubey MP, Srimal RC, Nityanand S, et al. Pharmacological studies on coleonol, a hypotensive diterpene from Coleus forskohlii. $J$ Ethnopharmacol. 1981;3(1):1-13.

19. Thida Intharachatorn, Rungrudee Srisawat. Antihypertensive Effects of Centella asiatica Extract. International Conference on Food and Agricultural Sciences IPCBEE. 2013;55(23).

20. Duarte J, Pérez-Palencia R, Vargas F, et al. Antihypertensive effects of the flavonoid quercetin in spontaneously hypertensive rats. $\mathrm{Br} J$ Pharmacol. 2001;133(1):117-124.

21. Nayak S, Nayak S, Dash DP, et al. A Clinical Study on the Effect of Boerhaavia Diffusa (Punarnava) in Essential Hypertension. Ayushdhara. 2015;2(6):390-396.
22. Sakat SS, Wankhede SS, Juvekar AR, et al. Antihypertensive effect of aqueous extract of Elaeocarpus ganitrus Roxb. seeds in renal artery occluded hypertensive rats. International Journal of Pharm Tech Research. 2009;1(3):779-782.

23. Maryaet BH, Bothara SB. al; Investigation of Antihypertensive activity of Leaves of Barleria Prionitis in Doca Salt Induced Hypertensive Rats. Int J Pharm Sci Rev Res. 2012;18(2):17-19.

24. Vakil RJ. A clinical trial of Rauwolfia serpentina in essential hypertension. Br Heart J. 1949;11(4):350-355.

25. Bello CT, Turner LW. Reserpine as an antihypertensive in the outpatient clinic: a double-blind clinical study. Am J Med Sci. 1956;232(2):194197.

26. Shah AJ, Gilani AH. Blood Pressure - Lowering and Vascular Modulator Effects of Acorus Calamus Extracts are Mediated Through Multiple Pathways. J Cardiovasc Pharmacol. 2009;54(1):38-46.

27. Joshi UH, Dabhi KR, Desai TR, et al. Investigation of antihypertensive mechanism of Evolvulus alsinoides in DOCA salt induced hypertensive rats. Int J Pharm Sci. Rev Res. 2012;5(7):3613-3617.

28. Asgary S, Naderi GH, Sarrafzadegan N. Antihypertensive and antihyperlipidemic effects of Achillea wilhelmsii. Drugs Exp Clin Res. 2000;26:89-93. 